\title{
Gender bias in the allocation of student grants
}

\author{
Marjolijn N. Wijnen ${ }^{1,2}$. Jorg J. M. Massen ${ }^{1,3} \cdot$ Mariska E. Kret $^{1,2}$ (D)
}

Received: 8 April 2020 / Accepted: 1 April 2021 / Published online: 31 May 2021

(C) The Author(s) 2021

\begin{abstract}
Multiple studies have shown that women's likelihood of receiving research funding is lower than that of their male colleagues. Thus far, all research on this gender gap in academia has focused on post-PhD academics, making it difficult to discern whether the female disadvantages in number of publications, previous grants, maternity leave, and h-indexes are at the root of the gender gap in received funding, or whether it is due to a more fundamental gender bias in academia. Therefore, we investigated whether female university students are already disadvantaged in receiving their first grant in their scientific career. We analysed data on applications $(N=2651)$ from 1995 to 2018 to the Leiden University International Study Fund (LISF), a fund dedicated to support students to study or conduct research abroad. We found that men and women applied equally often to the LISF. However, women had a lower success rate, which seemed to only get worse over recent years. Furthermore, male and female applications were assessed to be equal in quality when gender-related information was removed from them. The current study demonstrates that the factors that were assumed to contribute the most to the gender gap in more senior academics (e.g. previous grants, h-index) do not explain it fully: even when those factors do not yet play a role, such as in our student sample, women were found to have lower success rates than men. This underscores the importance of attacking gender biases at its roots.
\end{abstract}

Keywords Early career gender bias · Grant funding - Gender bias trend - Award success · Gender gap in science

\section{Introduction}

In the twenty-first century, women are still underrepresented in high positions in academia (European Commission, 2016). They advance to higher positions more slowly than men do and leave scientific careers in disproportionate numbers (Burrelli, 2008; Goulden et al.,

Mariska E. Kret

m.e.kret@fsw.leidenuniv.nl

1 Cognitive Psychology Unit, Faculty of Social and Behavioural Sciences, Institute of Psychology,

Leiden University, Wassenaarseweg 52, 2333 AK Leiden, The Netherlands

2 Leiden Institute for Brain and Cognition (LIBC), Albinusdreef 2, 2300 RC Leiden, The Netherlands

3 Animal Ecology Group, Utrecht University, Padualaan 8, $3584 \mathrm{CH}$ Utrecht, The Netherlands 
2011; Heijstra et al., 2015; Johnson, 2016). Additionally, multiple studies have shown that women's likelihood of receiving research funding is lower than that of their male colleagues (Bornmann et al., 2007; Bornmann et al., 2008; European Commission, 2019; Steinthórsdóttir et al., 2020; Van der Lee \& Ellemers, 2015) and it is unclear whether this is the result or the cause of a less successful career. Thus far, all research on gender biases in academia has focused on post-PhD academics, making it difficult to disentangle cause and consequence of the situation. For students at the Bachelor or Master level, factors such as publications, previous grants, maternity leave, and h-indexes that contribute to enlarging the gap between men and women in science do not yet play a major role. To assess whether the existing gender patterns in academia are the result of a fundamental gender bias, the current study addresses whether gender differences are already of influence amongst (under)graduate students (pre-PhD level) applying for a grant to fund a study-related stay abroad.

A potential cause of the skewed gender ratio in funding received might be women applying less often than their male colleagues. Indeed, it was found that only $15.3 \%$ of all applicants of the multidisciplinary Australian Research Council were female (Marsh et al., 2008). However, a more recent study conducted in the Netherlands showed that the proportion of female applicants to the prestigious Dutch Veni-grant for early-career researchers was much higher: 42.1\% (Van der Lee \& Ellemers, 2015). The difference between these reported numbers might be explained by results from the United States National Institutes of Health awards: in the categories for early-career researchers, the average application rates over all programs were approximately equal for men and women, whereas men are represented significantly more in the advanced researchers' competitions than women are (Pohlhaus et al., 2011). It is, though, important to compare female application proportions to the total proportion of potential female applications in order to draw substantial conclusions on gender (in)equality in application rates. For example, a female application rate of $50 \%$ within the field of psychology may sound good at first, but taking into account that $80 \%$ of the students is female (at least at our own institute) changes the interpretation of that initial percentage. This also applies to career stage, as typically, fewer females can be found at the higher levels. When examining all applications to both the Wellcome Trust in bioscience and the Medical Research Council, it was found that even though $44 \%$ of all academic staff in medicine and biosciences in the United Kingdom were female, only roughly $20 \%$ of all applications were submitted by women (Grant et al., 1997). The current study aims to gain more insight into whether women indeed apply less often. If application rates are equal for male and female university students when the total pool of potential applicants is controlled, factors like previous grants and publication rates may in fact be contributing to the differences that are found between male and female scientists at the post-PhD level. It is thus beneficial to investigate a student sample.

Secondly, multiple studies have found that women are less successful in receiving research funding than men (Bornmann et al., 2007; Bornmann et al., 2008; European Commission, 2019; Steinthórsdóttir et al., 2020; Van der Lee \& Ellemers, 2015), often independent of their application rates. Overall, across the European Union, success rates for scientific funding are 3\% higher for men than they are for women (European Commission, 2019). In a meta-analysis of 21 studies on grants awarded in a peer review process, similar results were found: men had greater odds of receiving a grant than women by about $7 \%$ (Bornmann et al., 2007). Strikingly, when investigating the University of Iceland Research Fund from 2010 to 2014, it was found that for every grant awarded to a woman, men received between 1.5 and 2.0 grants (Steinsthórsdóttir et al., 2020). Such a clear advantage for men was also found in the data of the Swiss National Science Foundation from 
2004 to 2006: men had 26\% greater odds of approval than women (Bornmann et al., 2008). A study in the Netherlands on the Veni-grant specifically reported both the proportion of female applications (42.1\%) and the proportion of female grant-allocations (37.9\%), showing women are indeed skimmed over and thus have lower success rates independent of application rates (Van der Lee \& Ellemers, 2015). However, more recent numbers on the more advanced Vici-grant awarded in 2019 in the Netherlands, show an opposite pattern: of all applications $35 \%$ were by women, and $65 \%$ by men, whereas of all grants allocated, $56 \%$ were to women and only $44 \%$ to men (NWO, 2020).

Since the issue of a gender bias against women has become more apparent in the last years, and many campaigns have been launched to combat it, we might expect that the negative consequences for women in science are decreasing. Indeed, it was reported that the ratio of male to female funding success rate decreased with $2.4 \%$ between 2010 and 2013 in European countries (European Commission, 2016). However, this positive trend was not reported in all studies. For instance, Head et al. (2013) investigated grants awarded specifically in infectious disease research in the United Kingdom over the years 1997 to 2010. The results showed that, compared to male applicants, women had lower success rates overall, and that these success rates for women had not consistently improved over the years. If an overall improvement is seen in success rates for scientists at the post-PhD level, it is important to verify that this trend replicates in a student sample. Since receiving a grant often makes it easier to acquire a second grant (Reinhart, 2009), success rates at the earliest possible career stage should be safeguarded. In the current study, we aim to further investigate the trend in female success rates over the years 1995 to 2018 focusing specifically on a student sample.

A gender imbalance in earning power might arise through direct discrimination, but it may also be related to men having better circumstances under which they can perform their scientific studies which makes them better prepared to submit proposals of a generally higher quality (Viner et al., 2004). This hypothesis, however, receives little support, i.e. several studies report that the differences in success rates found were explicitly attributable to women being assessed less favourably and not due to the lower quality of their proposals (Van der Lee \& Ellemers, 2015; Witteman et al., 2019). The current study aims to extend this research by investigating the putative difference in assessed quality of grant applications between male and female applicants in a student sample.

In conclusion, different studies have shown that overall, female researchers are disadvantaged in terms of research funding. Part of this difference may be due to women applying less. We further expect that women have a lower success rate than men when they do apply.

In this study, we specifically aim to investigate putative gender biases in grant allocation within the student population. We therefore investigate gender equality in the student grant application process at the Leiden University International Study Fund (LISF), a high-regarded competitive fund dedicated to support students to study or conduct research abroad. This grant distinguishes itself from other well-known international grants for students in Europe (e.g. Erasmus + for European exchange students) by its strict selection policy based on not only satisfying the eligibility requirements (such as is the case for the Erasmus + grant) but also a thorough application process including a student's resume, grade list, motivation letter, explanation of the project, arguments of the project's value for their studies and career and finally, a face-to-face interview. Because female students are probably not yet disadvantaged in such a way that the quality of their applications or the strength of their resumes is consistently lower than that of their male counterparts, investigating a gender bias in this sample provides a valuable asset to the existing literature. 


\section{Method}

\section{Study sample}

The study sample consists of Leiden University students who applied for a LISF student grant to finance their stay abroad during the period 1995 up until and including 2018. All applicants recorded in any of the official documents that could be found in the LISF on- or offline archives were included. After removal of applications that were archived double or withdrawn before the assessment process started $(N=82)$, this data set includes $N=2809$ applications in total (31.8\% were male, $62.8 \%$ female, and $5.4 \%$ of unknown gender). The applicants of whom gender was unknown $(N=152)$ were excluded from the statistical analyses, as were those of whom it is unknown whether they were awarded a grant or not $(N=6)$, making the final sample consist of $N=2651$ applications. See Table 1 for a demographic overview of applicants over the years. Due to scarce and unreliable information on the category of the applications (i.e. what the student will use the grant for: a research project or taking courses), we were not able to further divide the data set into subsamples based on these categories.

For a follow-up control experiment on the assessed quality of applications, we investigated the applications of a new cohort of students. This second sample included all LISF applicants of the December 2019 round, which totalled $N=32$.

\section{Statistical analysis}

\section{Application rates}

First, in order to investigate whether men apply more than women, we computed the proportions of applications by women in each year. And, for each year, the proportion of female students at Leiden University, using data on the total numbers of students as provided by the Leiden University Administration and Central Services. Next, we computed difference scores by subtracting the proportion of female applications from the proportion of female students, per year. This created variable is tested against a test value of 0 using a one-sample $t$ test.

Table 1 Overview of applicants and success rates separated by gender and period

\begin{tabular}{|c|c|c|c|c|c|c|c|c|}
\hline \multirow[t]{2}{*}{ Period } & \multicolumn{3}{|l|}{ Male } & \multicolumn{3}{|c|}{ Female } & \multirow[t]{2}{*}{ Unknown } & \multirow[t]{2}{*}{ Total } \\
\hline & App & Succ & & App & Succe & & & \\
\hline 1995-1998 & 30 & 22 & $(73.3 \%)$ & 50 & 32 & $(64.0 \%)$ & 112 & 192 \\
\hline 1999-2002 & 158 & 112 & $(70.9 \%)$ & 280 & 198 & $(70.7 \%)$ & 29 & 467 \\
\hline 2003-2006 & 157 & 94 & $(59.9 \%)$ & 310 & 183 & $(59.0 \%)$ & 6 & 473 \\
\hline 2007-2010 & 210 & 119 & $(56.7 \%)$ & 469 & 247 & $(52.7 \%)$ & 2 & 681 \\
\hline 2011-2014 & 161 & 107 & $(66.5 \%)$ & 296 & 180 & $(60.8 \%)$ & 2 & 459 \\
\hline 2015-2018 & 176 & 148 & $(84.1 \%)$ & 360 & 276 & $(76.7 \%)$ & 1 & 537 \\
\hline Total & 892 & 602 & $(67.5 \%)$ & 1765 & 1116 & $(63.2 \%)$ & 152 & 2809 \\
\hline
\end{tabular}

The data here is presented in time periods of four years for the purpose of a concise table 


\section{Success rates}

Second, to investigate whether success rates of female applicants differ from those of male applicants, we ran a generalised linear mixed model (GLMM) with a binomial distribution (logit link) using lmer4 (Bates et al., 2015) in R (R Core Team, 2017), with the decision (i.e. grant awarded yes or no, coded as 1 and 0 respectively) as dependent variable. We entered gender (men versus women) as a fixed factor, and year as a random factor to control for differences in LISF's yearly budget and other random differences caused by time passing. If gender was found to significantly influence the likelihood of receiving a grant, we furthermore investigate whether this gender bias changed over the years by further including year sequentially as a fixed factor in the model, as well as the interaction between sequential years and gender.

All models were compared to their respective null-models containing random effects only. We report only those instances in which the null-model did not deviate significantly from the test model.

\section{Quality of applications}

One possibility is that men have a higher likelihood of obtaining a grant simply because they submit applications of better quality compared to women, meaning a potential difference found in favour of men is fair. To rule out this explanation, we removed all genderrelated information (i.e. names, pronouns, and pictures) from applications in the December 2019 round prior the LISF committee grading them. The grading of the applications by the committee then proceeded as usual: each committee member graded a subset of applications on a scale from 5 to 7 , resulting in three grades per application. To test whether there was a difference in the grades of male applications in comparison to female applications, we ran a Mann Whitney $U$ test with gender as independent variable and the given grades as dependent variable.

\section{Results}

\section{Application rates}

To investigate whether women applied for the grant equally often as men, a one-sample $t$ test was conducted comparing the yearly difference scores (the proportions of female students subtracted by the proportions of female applicants) to a test value of 0 . The results show that this difference $\left(M_{\text {diff }}=0.04\right)$ does not significantly differ from $0, t(23)=1.28$, $p=0.212$, thus demonstrating the proportion of men and women applying for a grant, controlled for number of students, is the same.

\section{Success rates}

Secondly, we investigated whether the success rate of receiving a LISF grant differed between male and female applicants, by performing a binomial GLMM with gender as a fixed factor and the decision as dependent variable, with year added as a random factor $(s d=0.501)$. As expected, the likelihood of receiving a grant was somewhat higher for male applicants than for female applicants $\left(b_{\text {gender }}=-0.176, z=-1.96, p=0.049\right)$. 
In order to specifically test whether this difference in success rate between men and women has declined since 1995, we added the year of application sequentially as a second fixed factor to the same model as well as the interaction between sequential year and gender. We found a positive, albeit non-significant, trend for time $\left(b_{\text {year }}=-0.037, z=1.75\right.$, $p=0.080$ ) suggesting that the likelihood of receiving a grant becomes larger over the years. We also found a non-significant trend for the interaction effect between gender and time $\left(b_{\text {gender*year }}=-0.029, z=-1.800, p=0.072\right)$, which shows that in contrast to what we predicted, the difference in success rates between men and women seems to become somewhat larger over time (Fig. 1).

\section{Quality of applications}

To be able to rule out that men simply submit applications of better quality, hence having a higher likelihood of receiving a grant, we compared the grades assigned to the anonymous applications by the grant committee from the December 2019 round using a Mann Whitney $\mathrm{U}$ test. We found no significant difference in the assessed quality of submitted applications between men and women, $U=95.0, z=-0.87, p=0.387$. Thus, a hypothetical difference in the quality of applications is unlikely to explain the observed gender difference in success rates.

\section{Discussion}

An important contributor to advancing in academia is the amount of grant money acquired. It is often found that women apply less (Grant et al., 1997; Marsh et al., 2008; Pohlhaus et al., 2011; Van der Lee \& Ellemers, 2015; Viner et al., 2004) and succeed

Fig. 1 Percentage of grant applications awarded for male and female students over the years, showing an increased likelihood for both, but more so for men

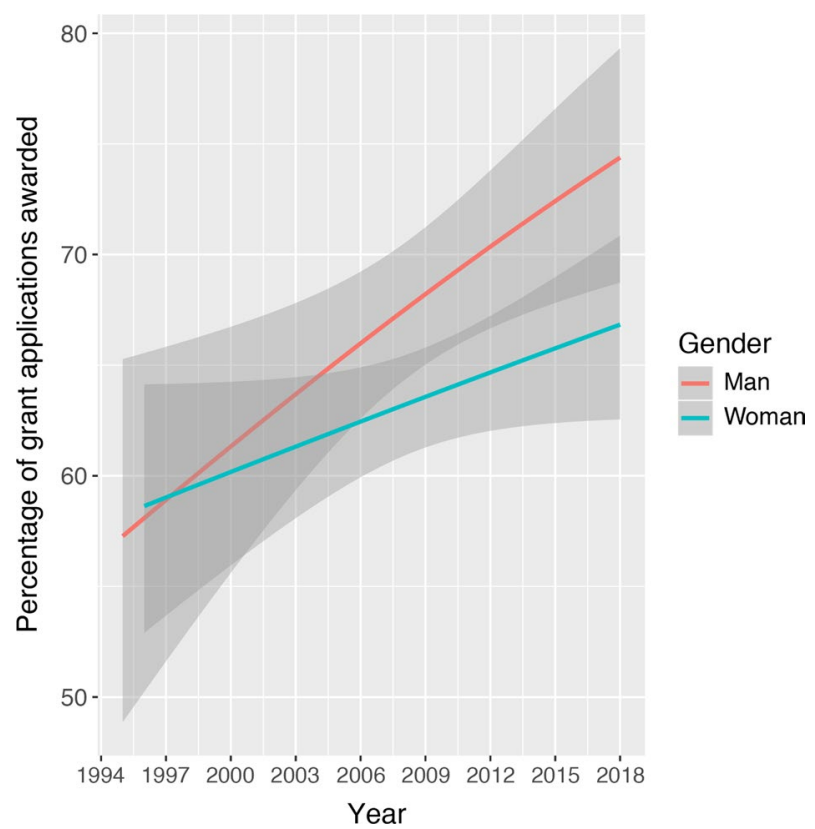


less often (Bornmann et al., 2007; Bornmann et al., 2008; European Commission, 2019; Steinthórsdóttir et al., 2020; Van der Lee \& Ellemers, 2015). This could thus be one of the key causes for women having less successful scientific careers. In what seems to be a vicious circle, it is difficult to disentangle cause from consequence. To gain more insight into this matter, we investigated a university student sample for which factors such as publications, previous grants, maternity leave, and h-indexes that contribute to enlarging the gap between men and women in science do not yet play a substantial role. Consequently, we asked whether the above-mentioned differences in career success between men and women rely on a sequence of events, or on a more fundamental, institutionalised gender bias in academia, i.e. are female students already disadvantaged in receiving what is in all probability their first grant in their scientific career?

In short, we demonstrated that female students apply equally often for a grant to study or conduct research abroad as their male counterparts. Yet, they are less successful in actually receiving this funding, and this bias does not seem to have improved over recent years. Instead, it seems to get larger. This difference could not be explained by a difference in the quality of applications by male and female students, as applications were assessed to be equal when all gender information was removed. In the following sections, we discuss these results in the context of the existing body of literature and aim to identify potential underlying causes. We conclude with a section on the limitations and recommendations for further research and measures to take in the field of gender equality.

\section{Application rates}

In our student sample, we found that when application rates to the LISF were corrected for the total student population rates (i.e. potential applicants), female students apply equally often as male students. This is in direct contrast to the results of Grant et al. (1997), who showed a loss of roughly $20 \%$ from potential applicants to actual applicants. Potential reasons for this contrasting finding might be that our data is more recent. Possibly, over time, women might have become more ambitious and/or confident in their abilities to be scientists. Gender is on the agenda of many organisations, universities included. Nowadays, female scientists are also frequently seen in the media, serving as role models for female students. Additionally, our data is on a pre-PhD population whereas previous studies have focused on post-PhD researchers. This fits previous results that showed application rates to be more equal between the genders when early-career researchers were compared, than when advanced researchers were compared (Pohlhaus et al., 2011). Whereas successful women are often disapproved of and generally seen as unlikeable in contrast to successful men (Acker, 2009; Heilman, 2001; Heilman et al., 2004), the young generation has not had these stereotypical experiences yet: their hopes and ambitions are not yet diminished (Pololi \& Jones, 2010; Steele \& Aronson, 1995). Additionally, at student-age, many structural expectations and burdens that exist in society more so for women than for men, could not have had much of an influence yet. For example, women are oftentimes (expected to be) primary caretakers of their families. Hence, they have to put more effort into balancing family life whilst keeping up with their organisations' expectations. A risk of organisations' family friendly programs is that it may reinforce the idea that women with a family are not fully unencumbered (Acker, 2009). Women thus experience these extra burdens, in contrast to men, which does not leave room for applying for grants. 


\section{Success rates}

The results of the current study do show, however, that female applicants have a significantly smaller likelihood of receiving a grant than men, a difference of approximately 4\%. This is similar to some previously reported success rates of women (i.e. 7\%: Bornmann et al., 2007; 3\%: European Commission, 2019). Since our data is on a student population, previously reported potential causes for lower success rates for women, such as lower reputation indices (Eagly \& Miller, 2016; Geraci et al., 2015; Hirsch, 2005), lower publication rates (European Commission, 2016), and lower citation rates (Dion et al., 2018; Maliniak et al., 2013), do not seem to fully explain the gender gap. Traditional gender roles which may deem women unfit for leadership roles, including principal investigators in lead of a research team (Acker, 2009; Eagly \& Karau, 2002; Heilman, 2001), may be of influence too. Women may conform to this stereotype, but grant committees may also enforce them. Due to increased attention to gender differences and stereotypes, and several campaigns that have recently been launched, the gender gap is thought to have become smaller with time, as reinforced by, for example, reported numbers by the European Commission (2016). However, this does not hold up in our data: over time, the overall likelihood of receiving a LISF grant has increased, but mostly for men and less so for women. Apparently, young women at the earliest stages in their scientific careers are already disadvantaged in terms of awarded grants, and this seems to have gotten only worse over recent years. This, then, further disadvantages them in proceeding their career: recently graduated students whose resumes state they have received funding during their studies are advantaged in comparison to students who have not received such funding. It was indeed found that those who have previously received funding publish significantly more successfully than those who were rejected, and are cited twice as many times per publication in the five years following funding (Reinhart, 2009).

\section{Quality of applications}

In order to be able to place the above-described results in a broader perspective, we conducted a follow-up investigation into the quality of applications by men and women. We found that when applications were anonymous, the quality was evaluated to be equal by the LISF grant committee. This is in line with our expectation: the students are still early in their career and have no experiences yet with publications or previous grant successes or failures. Therefore, resumes of male and female students were expected to be of equal quality. We also had no reason to expect qualitative differences in the project ideas the students submitted. The fact that we still found a difference in success rates between the genders when applications were not anonymous, further reinforces the idea that this difference is explicitly attributable to the difference in gender as can be identified on the application and not the quality of the application itself (Van der Lee \& Ellemers, 2015; Witteman et al., 2019). This is further shown to be true in the academic job application procedure: despite having equal resumes as male applicants, women are evaluated less favourable (Moss-Racusin et al., 2012). This probably means that female applications have to be of higher quality to receive the same results relative to male applications. 


\section{Conclusion}

The current study shows that female scientists-to-be are as ambitious as their male counterparts and apply for grants equally often. However, even at this young age, women have lower success rates than men. It is very unlikely that this is a result of differences in quality since the applications of men and women from a comparable sample of students were judged of equal quality when reviewed blindly. This shows that factors such as publications, previous grants, maternity leave, and h-indexes do not (fully) explain the gender gap in science. The current study underscores the importance of addressing gender bias at a very early career stage, perhaps even earlier than the sample tested here, in order to accomplish improvements at a later stage.

\section{Limitations and recommendations}

Since many proposed causes for differences between the genders in received funding have not proved to explain the gender gap fully, further research should focus on why a difference in success rates can already be found in university students.

It is possible that the direction of differences between the genders in success rates differ per field of science. For example, Bornmann et al. (2008) found lower success rates for women overall, but this was primarily due to differences between the genders in specific biological and medical fields. It could be that the gender bias found in the current study is restricted to or even reversed in certain fields of science: a so-called Simpson's Paradox (Bickel et al., 1975; Blyth, 1972; Simpson, 1951). We might expect women to be more disadvantaged in those fields that are traditionally more male-dominated than in disciplines where the majority of students are female. We did not further investigate differences in the disciplines as the current sample was too small for this, and many changes had occurred since 1995 in officially registered majors of study (e.g. some were combined over the years, some disappeared, etc.).

Secondly, it has been suggested that the gender composition of those deciding whether an applicant should receive a grant or not, might influence that decision. It is found, for instance, that small preferences of reviewers towards certain classes, regardless of whether they are conscious preferences, might have large effects on the decision of awarding a grant or not to those belonging to these classes (Day, 2015). Based on a study done by Massen et al. (2017) we might assume both genders' preferred class is men, since they observed that men are most likely to share their science with other men, more so than any other possible combination of genders. The hesitance of female scientists to share with others was also found in grant approval probabilities specifically: in the Austrian Science Fund, when at least half of the group of reviewers was female, grant approval decreased with $10 \%$ regardless of applicant gender (Mutz et al., 2012). The LISF application process involves three stages: grading of the application by three reviewers, an interview with the applicant by two reviewers, and final deliberation with the full committee. Since the gender composition differs over all these three stages, it is difficult to deduce the potential effect of reviewer gender on the grant decision in the current sample.

A further conceptual limitation of research on gender, such as the current study, is the limited definition of gender as we have known it. Applicants have never been required to indicate their gender for the LISF, and is quite possibly also not asked in other grant 
applications either. By assuming the binary gender of applicants, and assuming a bias towards either of them exists, whether it be conscious or unconscious, we exclude the discussion on the concept of gender as a whole. While this does not take away any importance from studying the continuous gender bias against women in comparison to men in science and other high functions, this research is not inclusive of the existent diversity of genders.

Acknowledgements We thank the committee members of the Leiden University International Study Fund (LISF) for their kind support for this study. Additionally, we want to thank Chris Riddell for proofreading the manuscript.

Funding Research was supported by the Netherlands Science Foundation (016.VIDI.185.036) from NWO (Nederlandse Organisatie voor Wetenschappelijk Onderzoek) and the European Research Council (ERC) (Starting Grant \#802979) to Mariska E. Kret.

\section{Declarations}

Conflicts of interest Not applicable.

Ethics approval The Psychology Ethics Committee of Leiden University approved this study under the processing number CEP18-0704/299.

Consent to participate Not applicable.

Consent for publication We hereby declare that this manuscript is not submitted or under review at another journal. All authors have agreed on the submission of this version of the manuscript.

Availability of data, code, and material All data, code, and materials that are associated with this paper and used to conduct the analyses will become accessible at Leiden University archiving platform DataverseNL when published.

Open Access This article is licensed under a Creative Commons Attribution 4.0 International License, which permits use, sharing, adaptation, distribution and reproduction in any medium or format, as long as you give appropriate credit to the original author(s) and the source, provide a link to the Creative Commons licence, and indicate if changes were made. The images or other third party material in this article are included in the article's Creative Commons licence, unless indicated otherwise in a credit line to the material. If material is not included in the article's Creative Commons licence and your intended use is not permitted by statutory regulation or exceeds the permitted use, you will need to obtain permission directly from the copyright holder. To view a copy of this licence, visit http://creativecommons.org/licenses/by/4.0/.

\section{References}

Acker, J. (2009). From glass ceiling to inequality regimes. Sociologie du travail, 51, 199-217

Bates, D., Maechler, M., Bolker, B., \& Walker, S. (2015). Fitting linear mixed-effects models using lme4. Journal of Statistical Software, 67(1), 1-48

Blyth, C. R. (1972). On Simpson's Paradox and the sure-thing principle. Journal of the American Statistical Association, 67(338), 364-366

Bickel, P. J., Hammel, E. A., \& O'Connell, J. W. (1975). Sex bias in graduate admissions: Data from Berkeley. Science, $187,398-404$

Bornmann, L., Mutz, R., \& Daniel, H.-D. (2007). Gender differences in grant peer review: A meta-analysis. Journal of Informetrics, 1, 226-238

Bornmann, L., Mutz, R., \& Daniel, H.-D. (2008). How to detect indications of potential sources of bias in peer review: A generalized latent variable modeling approach exemplified by a gender study. Journal of Informetrics, 2, 280-287 
Burrelli, J. (2008). Thirty-three years of women in S\&E faculty positions (Publication No. NSF 08-308). Arlington, VA: National Science Foundation. Retrieved from http://www.nsf.gov/statistics/infbrief/ nsf08308/nsf08308.pdf

Day, T. E. (2015). The big consequences of small biases: A simulation of peer review. Research Policy, 44, 1266-1270

Dion, M. L., Sumner, J. L., \& Mitchell, S. M. (2018). Gendered citation patterns across political science and social science methodology fields. Political Analysis, 26, 312-327

Eagly, A. H., \& Karau, S. J. (2002). Role congruity theory of prejudice toward female leaders. Psychological Review, 109(3), 573-598

Eagly, A. H., \& Miller, D. I. (2016). Scientific eminence: Where are the women? Perspectives on Psychological Science, 11(6), 899-904

European Commission: Directorate-General for Research and Innovation. (2016). She figures 2015. Luxembourg: Publications Office of the European Union.

European Commission: Directorate-General for Research and Innovation. (2019). She figures 2018. Luxembourg: Publications Office of the European Union.

Geraci, L., Balsis, S., \& Busch, A. J. (2015). Gender and the h index in psychology. Scientometrics, 105(3), 2023-2034

Goulden, M., Mason, M. A., \& Frasch, K. (2011). Keeping women in the science pipeline. The Annals of the American Academy of Political and Social Science, 638(1), 141-162

Grant, J., Burden, S., \& Breen, G. (1997). No evidence of sexism in peer review. Nature, 390, 438

Head, M. G., Fitchett, J. R., Cooke, M. K., Wurie, F. B., \& Atun, R. (2013). Differences in research funding for women scientists: A systematic comparison of UK investments in global infectious disease research during 1997-2010. British Medical Journal Open, 3(12), e003362

Heijstra, T., Bjarnason, T., \& Rafnsdóttir, G. L. (2015). Predictors of gender inequalities in the rank of full professor. Scandinavian Journal of Educational Research, 59(2), 214-230

Heilman, M. E. (2001). Description and prescription: How gender stereotypes prevent women's ascent up the organizational ladder. Journal of Social Issues, 57(4), 657-674

Heilman, M. E., Wallen, A. S., Fuchs, D., \& Tamkins, M. M. (2004). Penalties for success: Reactions to women who succeed at male gender-typed tasks. Journal of Applied Psychology, 89(3), 416-427

Hirsch, J. E. (2005). An index to quantify an individual's scientific research output. Proceedings of the National Academy of Sciences of the United States of America, 102(46), 16569-16572

Johnson, H. L. (2016). Pipelines, pathways, and institutional leadership: An update on the status of women in higher education. Washington: American Council of Education.

Maliniak, D., Powers, R., \& Walter, B. F. (2013). The gender citation gap in international relations. International Organization, 67(4), 889-922

Massen, J. J. M., Bauer, L., Spurny, B., Bugnyar, T., \& Kret, M. E. (2017). Sharing of science is most likely among male scientists. Scientific Reports, 7, 12927

Marsh, H. W., Jayasinghe, U. W., \& Bond, N. W. (2008). Improving the peer-review process for grant applications. Reliability, validity, bias, and generalizability. American Psychologist, 63(3), 160-168

Moss-Racusin, C. A., Dovidio, J. F., Brescoll, V. L., Graham, M. J., \& Handelsman, J. (2012). Science faculty's subtle gender biases favor male students. Proceedings of the National Academy of Sciences of the United States of America, 109(41), 16474-16479

Mutz, R., Bornmann, L., \& Daniel, H.-D. (2012). Does gender matter in grant peer review? An empirical investigation using the example of the Austrian science fund. Zeitschrift für Psychologie, 220(2), $121-129$

NWO (2020). Vici awards 2019. https://www.nwo.nl/en/research-and-results/programmes/nwo/talentscheme/vici-awards-2019.html

Pohlhaus, J. R., Jiang, H., Wagner, R. M., Schaffer, W. T., \& Pinn, V. W. (2011). Sex differences in application, success, and funding rates for NIH extramural programs. Academic Medicine, 86(6), 759-767

Pololi, L. H., \& Jones, S. J. (2010). Women faculty: An analysis of their experiences in academic medicine and their coping strategies. Gender Medicine, 7(5), 438-450

R Core Team. (2017). R: A language and environment for statistical computing. Vienna: R Foundation for Statistical Computing.

Reinhart, M. (2009). Peer review of grant applications in biology and medicine. Reliability, fairness, and validity. Scientometrics, 81(3), 789-809

Simpson, E. H. (1951). The interpretation of interaction in contingency tables. Journal of the Royal Statistical Society, 13(2), 238-241

Steele, C. M., \& Aronson, J. (1995). Stereotype threat and the intellectual test performance of African Americans. Journal of Personality and Social Psychology, 69(5), 797-811 
Steinsthórsdóttir, F. S., Einarsdóttir, T., Pétursdóttir, G. M., \& Himmelweit, S. (2020). Gendered inequealities in competitive grant funding: An overlooked dimension of gendered power relations in academica. Higher Education Research ands Development, 39(2), 362-375

Van der Lee, R., \& Ellemers, N. (2015). Gender contributes to personal research funding success in the Netherlands. Proceedings of the National Academy of Sciences of the United States of America, 112(40), 12349-12353

Viner, N., Powell, P., \& Green, R. (2004). Institutionalized biases in the award of research grants: A preliminary analysis revisiting the principle of accumulative advantage. Research Policy, 33, 443-454

Witteman, H. O., Hendricks, M., Straus, S., \& Tannenbaum, C. (2019). Are gender gaps due to evaluations of the applicant or the science? A natural experiment at a national funding agency. The Lancet, 393, 531-540 